\section{Psychophysics discovers Piaget: Comments on Frayman and Dawson (1981)}

\author{
ROBERT P. O'SHEA \\ Department of Humanities and Social Sciences \\ Darwin Community College \\ Winnellie, Northern Territory 5789, Australia
}

I was surprised that neither Frayman and Dawson (1981) or their reviewers seemed to be aware of the relevance of Piaget's work (e.g., Inhelder \& Piaget, 1958; Piaget, 1928, 1952; Piaget \& Inhelder, 1974) to their studies. Frayman and Dawson required 20 introductory psychology students to estimate the volume of a range of either solid shapes of known volumes or pictorial representations of the solids. The subjects made magnitude estimates which were related to the actual volumes by power functions. However, in their first two experiments, Frayman and Dawson noticed that the exponent for cylinders was slightly greater than that for other shapes (such as cubes and spheres), and that the volumes of cylinders and tetrahedrons were overestimated. For cylinders, the height:width ratio was $2: 1$ for all volumes. Frayman and Dawson suggest that the height of the cylinders is crucial: "cylinders ... differ from the other ... shape classes [tested] in possessing an elongated vertical dimension ..., at any volume they 'tower' over ... other shapes"' (p. 59). By way of support, Frayman and Dawson cite similar results from other psychophysical studies and mention the horizontal-vertical illusion as a two-dimensional analog of their finding. In their third experiment, Frayman and Dawson parametrically varied the height and diameter of cylinders and gathered magnitude estimates. The salience of the dimension of height was borne out by the results of 20 naive students. Overall, tall narrow cylinders were judged to have greater volume than short wide cylinders of equal physical volume.

Frayman and Dawson suggest that the influence of height is "a basic principle" (p. 61). An examination of the work of Piaget would have lead them to realize that there was some precedent for the basic principle. Piaget is generally regarded as one of the pioneers of developmental psychology, and is particularly noted for his studies of cognition (e.g., see Watson, 1971; Wertheimer, 1970). He suggested that there is a developmental sequence of qualitatively different stages in the understanding of formal logi-

I am grateful to Boris Crassini, Graeme Halford, and Ted Milliken for their comments on earlier versions of this note. cal operations, and used the concept of the conservation of quantity as his most famous illustration of passage through the sequence. Piaget found that children between the ages of about 4 and 7 years make judgments of volume which seem to be based solely on one dimension of the quantity being judged. For example, he found that children will assert that a tall narrow glass contains more liquid than does a short wide container, despite agreeing beforehand that the two volumes were equal when in equivalently shaped vessels. This "centration" on one particular stimulus dimension (in this case, height) is characteristic of the stage of thinking Piaget termed "preoperational." Furthermore, centration is evident in children's responses to a number of tasks Piaget devised to demonstrate the preoperational stage (such as failure of class inclusion, failure to make transitive inferences, and failure on conservation of number and mass as well as volume).

According to Piaget, children become able to pass conservation problems when they can simultaneously consider more than one stimulus dimension at a time. This is supposed to occur at around 7 years of age. It could be that the work of Frayman and Dawson has confirmed what every teacher of introductory psychology suspects: that their students are still at the preoperational stage of cognitive development (but cf. Neimark, 1975)! If not, then their results are intriguing. While adults may be able to pass conservation problems in which they see the transformation of a constant volume from a short wide shape to a tall narrow shape, the primitive, preoperational centration on height seems to reemerge when the information is lacking (cf. Odom, 1978).

Frayman and Dawson's procedure eliminates the obvious clue of seeing one shape transformed into another. In gathering subjects' estimates of the reality of the situation, Frayman and Dawson may be testing a rather specific piece of information. Consider the geometry of one of their stimuli. Volume of a cylinder is linearly related to its height but to the square of its radius. This means that a doubling of the height while the radius is kept constant produces a doubling in volume; but doubling the radius produces a fourfold increase in the volume. It would be of interest to determine how much of the variability in the volume estimates of Frayman and Dawson's students is accounted for by knowledge or ignorance of this relation. In any case, it seems that Frayman and Dawson have stumbled onto a new conservation task which may force a revision of when the transition from preoperational to operational thinking occurs. 


\section{REFERENCES}

Frayman, B. J., \& Dawson, W. E. The effect of object shape and mode of presentation on judgments of apparent volume. Perception \& Psychophysics, 1981, 29, 56-62.

INHELder, B., \& PIAGET, J. The growth of logical thinking from childhood to adolescence (A. Parsons \& S. Milgram, trans.). New York: Basic Books, 1958.

Neimark, E. D. Intellectual development during adolescence. In F. D. Horowitz (Ed.), Review of child development research (Vol. 4). Chicago: University of Chicago Press, 1975.

ODом, R. D. A perceptual salience account of decalage relations and developmental change. In L. S. Siegel \& C. J. Brainerd (Eds.), Alternatives to Piaget: Critical essays on the theory. New York: Academic Press, 1978.
Piaget, J. Judgement and reasoning in the child (M. Warden, trans.). London: Routledge \& Kegan Paul, 1928.

Pinget, J. The origins of intelligence in children (M. Cook, trans.). New York: International Universities Press, 1952.

Pinget, J., \& Inhelder, B. The child's construction of quantities: Conservation and atomism (A. J. Pomerans, trans.). London: Routledge \& Kegan Paul, 1974.

Watson, R. I. The great psychologists from Aristotle to Freud (3rd ed.). Philadelphia: Lippincott, 1971.

Wertheimer, M. A brief history of psychology. New York: Holt, Rinehart \& Winston, 1970.

(Manuscript received July 8, 1981; accepted for publication July 9, 1981.) 